\title{
Enhancing Human Choice by Information Technologies
}

\author{
Tanja Urbancic, Olga Stepankova, and Nada Lavrac \\ Nova Gorica Polytehnic, Slovenia; tanja.urbancic@p-ng.si \\ Jozef Stefan Institute, Ljubljana, Slovenia; nada.lavrac@ijs.si \\ Czech Technical University, Prague, Czech Republic; \\ step@labe.felk.cvut.cz
}

\begin{abstract}
The paper discusses what the research community in the field of information technologies can do to improve quality of life by offering more alternatives both to individuals and to the society. Moreover, attention is given to the present IT tools which can be used to support decision making and choice among possible alternatives in complex settings. The role of ITs in achieving this goal is explained and illustrated by examples in different fields, including environmental decision-making and health care. Enhanced possibilities of choice in collaborative settings supported by new media and computer networks are also shown. Besides the role of ITs that support this enhancement, the importance of non-technological aspects is presented with special emphasis on responsibility and network intelligence.
\end{abstract}

Keywords: human choice, human-computer interface, data mining, collaborative decision-making, networked organizations.

\section{Introduction}

The responsibility of science and technology towards the society has increasing importance, since accumulated consequences of short-sighted decisions and actions of the human race in the past make it more and more difficult to bring things into balance [McKibben, 2004]. An important step was done by [Bruntland, 1987] that introduced the notion of sustainable development and put it as a central question of our time. In 1999, ICSU/UNESCO World conference on Science, Budapest stated explicitly that science should be for knowledge, peace, development and society. Also declarations of IT professional communities are in accordance with this see for example the ACM Ethical Code from 1993. This code requires from ACM members,

Please use the following format when citing this chapter:

Urbancic, T., Stepankova, O., Lavrac, N., 2006, in IFIP International Federation for Information Processing, Volume 223, Social Informatics: An Information Society for All? In Remembrance of Rob Kling, eds. Berleur, J., Numinen, M. I., Impagliazzo, J., (Boston: Springer), pp. 255-264. 
among other, also to improve public understanding of computing and its consequences, and to design and build information systems which enhance the quality of working life [Kling, 1994]. Recent development proved that ITs are able to offer lot of support to each of us as an individual (a citizen or a professional) as well as to society as a whole. Due to Internet we are able to remain in contact with our family and friends at the far ends of the Earth as well as to find lot of up-to-date information, provided the following conditions hold: we have access to Internet, we are aware of the necessary technology, we can and we know how to use it. Internet represents a novel phenomenon, which can significantly change our life and improve functioning of our society, provided these three conditions are ensured. An obvious first step towards this goal is to guarantee geographical coverage by Internet. But this is not enough since there are many additional obstacles due to which IT is not directly available to everyone. Official resources confirm that only in Europe there is more that half million of people who cannot make use of mouse as a standard PC user interface due to their physical handicap. Number of challenged persons who need some sort of support in order to get access to Internet is even much higher since they represent at least $5 \%$ of present population. Of course, it is important to support development of better technical means fine-tuned to the needs of their users. But even that is not enough, since there are many additional economic and social reasons which hinder entrance of modern IT into various segments of society (e.g. in elderly population). and that is why the decision-makers stress the need to wipe off 'digital divide'.

We have to be aware of many more ways how present technology can impact or improve conditions of many individuals. In the second half of the 20th century there have appeared numerous technical devices (pacemakers, hearing aids, artificial kidney, etc.), which can significantly change quality of life of people whose health status cannot be described as average. Often, these solutions help to overcome difficulties and challenges which have been up to now considered as impassable: in laboratories of universities there are tested new devices which make up for various deficiencies, e.g. limited ability to move, to see, to hear or to remember. Unfortunately, most of these handy solutions are too expensive or too demanding (e.g. requiring invasive treatment of the patient or setting too much constraints on his/her behaviour) to become an available and attractive alternative for everyone who could benefit from it. That is why it is important to proceed one step further and insist on the need to design affordable solutions for the considered problems. We believe this can be achieved in many cases by combining means offered by new technical tools, information and communication technologies (ICT) and artificial intelligence.

In the global world, it is important to help humans in making wise choices, based on the best information and knowledge available. More knowledge means better choice, and good choice means one that is more in alignment with the long-term goals of human society.

In this respect, besides providing access to enormous amount of information at the World Wide Web any time from any place, information technologies are ready to help us in improving conditions of many individuals and of society as such

- by enhancing human potential of challenged persons through affordable solutions which let them overcome their handicap and ensure additional 
alternatives including those one could otherwise not be aware of, or one would not be able to explore,

- by helping to extract more knowledge from available data about the situation and to design various alternatives, giving foundation for better decision-making,

- $\quad$ by supporting decision-making process in complex situations,

- by enabling cooperative settings.

In the following sections, we discuss each of these possibilities in more detail. They are illustrated and commented through examples originating in personal experience of the authors and their co-workers from the research laboratories at the Department of Knowledge Technologies at the Jozef Stefan Institute, Ljubljana, at the Nova Gorica Polytechnic, and at the Department of Cybernetics of the Faculty of Electrical Engineering at the Czech Technical University, Prague.

\section{Offering New alternatives: Man-Computer Interaction for Handicapped People}

It is no doubt that there are many health problems we are not able to treat. Other problems can be improved by application of most sophisticated technology - this is the case of deficiencies related to some cognitive functions. After years of research cochlear implant is produced in massive scale now, it became an affordable tool and there are thousands of its users who enjoy its positive impact on their life [Chorost, 2005].

But sometimes the present technology is ready to be applied in much simpler way provided the scientists are able to identify the need and recognize the opportunity. Let us describe one of the affordable solutions, which was designed and developed at the Department of Cybernetics in Prague. It is the device I4Control [Fejtova and Fejt, 2005], a new computer periphery awarded the IST Prize 2006 (for details see http://cyber.felk.cvut.cz/i4c/en_system.html). I4Control' emulates the computer mouse - its distinguishing feature is the way it is controlled: while actuators of computer mouse are fingers this periphery reacts to the movements of eyes of its user. This feature makes it most useful to everyone who cannot use a keyboard or a traditional PC mouse to control a computer. This might be the case of people who lost their hands in an accident or patients with cerebral palsy who cannot move at all. For the last type of patients communication based on eye movements remains the only option. The user of I4Control' ${ }^{\prime}$ gets direct access to everything, what can be controlled by the PC mouse. Namely, this is the case of a software keyboard, which is nowadays a common part of an operating system. Consequently the I Control $^{\text {? }}$ user is ready to type using the software keyboard and he/she can write the text documents, send the e-mails, brows the web pages, etc. There are even cases when this device becomes a unique mediator between the paralyzed person and its environment (e.g. when the person cannot speak).

The main advantage of the 14 Control' solution is that it represents a technological solution, which is safe and available to everyone - it meets the demands of democratic AI. It can be produced in mass and nearly everybody can learn to use it. The device proved to be very well accepted by handicapped persons 
(e.g. a boy who lost both hands as a result of an accident or a boy with myopathy) who have learned to use it quickly [Fejtova et al., 2005]. An important feature is that the used I4Control' hardware is based on easily available and financially not demanding off-the-shelf components which are assembled into a simple, mobile, efficient and fault tolerant product with good resolution which can be easily installed at home of its user. The resulting computer periphery is not the first device ensuring gaze-based man-computer interaction. Certainly, it is the first one, which offers following significant advantages to its users:

- it does not pose on them any unnatural constraints: the user does not have to remain fixed in a single position (so that it does not interfere with his/her usual habits),

- the device is as easy to operate as glasses (it is absolutely non-invasive - there is no need to glue special marks etc.),

- it has affordable price and it is simple to install, moreover, the user needs no demanding instruction. The resulting periphery enables physically handicapped users to communicate with their environment or even work or study on their own.

\section{Getting More Knowledge from Data: Examples in Health Care}

Effective medical prevention and good access to health care resources are among the most important issues that contribute to the citizens' welfare and quality of life. As such, these issues have an important place in strategic plans at the level of regions, countries and even broader. In The European Health Report from 2002, WHO gives guidelines for assessment of national health systems, stating explicitly their objectives: good health of population, good availability and accessibility of health care services for patients and fair distribution of financial burdens of health care services.

Data collected in enormous quantities by medical institutions and governmental institutions responsible for public health care can serve as a valuable source of evidence that should be taken into account when deciding about priorities to be included into strategic plans, or when deciding about specific measures to solve a particular problem.

Data mining methods [Fayyad et al., 1996] [Han and Kamber, 2001] have big potential to support abovementioned activities and have already proved to be useful in many applications.

An example that offers a direct connection to the enhancement of choice is described in [Gamberger et al., 2003]. The authors use data mining for coronary heart disease (CHD) risk group detection. CHD is one of the world's most frequent causes of mortality and an important problem in medical practice. We know a lot about CHD risk factors and one concept of CHD prevention is general education of the whole population about them, especially about those related to life-style factors. Interestingly, the practical influence of this concept is estimated as small because people are not ready to accept the suggestions seriously before the occurrence of first 
actual signs of disease. (So we should not simplify and believe that problems are solved if people have information and possibility of choice.) Therefore, it is very important to apply the second concept, namely risk factor screening in general practice by data collection performed in three different stages: anamnestic information, laboratory tests and ECG at rest tests. The problem appears mostly in cases with slightly abnormal values and in cases of combinations of different risk factors. Gamberger, Lavrac and Krsti_ used data collected at the Institute for Cardiovascular Prevention and Rehabilitation in Zagreb, Croatia, as a basis for detecting patients at risk. They used the interactive Data Mining Server (DMS) available on-line for public use at $h t t p: / / d m s . i r b . h r$ and discovered several relatively simple rules that can either help in deciding whether a particular person needs further medical testing, or to efficiently organize systematic prevention testing to subpopulations in which proportionally many CHD patients can be expected. In this case, the results of data mining can directly support professional decision-making of medical doctors. The rules are simple enough also to be publicly announced together with a call to people who recognize themselves as being at risk to come for further tests, but of course, this should be done with precaution. Also, we should not expect that people will suddenly change their behavior and follow the recommendations, but this should not prevent anybody from giving them information and possibility to choose how they will react.

Another example of obtaining useful information from data in the field of public health care is presented in [Lavrac et al., 2005]. In this case, data mining and statistical techniques were used to analyze data collected by Celje regional Public Health Institute, in order to address the problem of relatively big differences in directing patients from primary health centres to specialists. The results of data mining were used for a more elaborate study using decision support techniques [Mallach, 2000]. The objective was to detect local communities that are underserved concerning general practice health care. The resulting representation was well accepted by the experts, as it clearly shows the distribution of the availability of health care resources for patients from different communities. The study later continued by the analysis of causes for different availability and accessibility of services, and has been recently completed for two additional regions within a project for the Slovenian Ministry of Health, in which also secondary level of health care (specialists and hospitals) was analyzed in a similar way. The analysis provides information needed for planning the health care providers network in accordance with the strategic goals of equal availability and accessibility of services for everybody.

\section{Supporting Collaborative Decision-Making: An Example in Environmental Planning}

There is no general consensus about how and to which extent public opinion should be taken into account in environmental decision-making. There are arguments that people don't have enough knowledge to predict the consequences of certain decisions, so their involvement would bring noise and bias into the decision-making 
process. On the other hand, environmental decisions may deal with questions that even experts cannot answer with certainty. What is certain is that laymen in each specific case will carry the burden of potential environmental damage, and this is why they should be involved in the decision-making process in spite of the issue of different and very often opposing interests and value systems. It is becoming clear that the assurance of a fair distribution of benefits and costs among different social groups is not just scientific, but also a social issue [Bedau, 1991].

The problem remains how to assure that a collaborative decision-making process in such a heterogeneous group of experts, local authorities and public would still lead to an operational result. In [Kontic et al., 2006] it was shown that a method of multiattribute decision modelling used in DEX [Bohanec and Rajkovic, 1990] offers a good foundation for a collaborative decision-making process in such cases, providing that the process is led by a skilled and knowledgeable moderator. DEX is a decision support system that has proved to be useful in many real life applications [Bohanec and Rajkovic, 1999].

The method was tested in a collaborative decision-making setting [Kontic et al,, 2006] at a workshop simulating a situation of selecting a site for a low and intermediate level radioactive waste repository in Slovenia. The participants were first equipped with basic knowledge and understanding of the method, and then exposed to problem-solving in groups that simulated realistic situation in which different backgrounds and interests had to be taken into account. The results show that due to the well defined procedures that guided the decision-making process, the participants were able to end up with surprisingly complex and fully reasonable decision models. This opens new perspectives in the practice of decision-making and offers new views on the dilemmas about public involvement in the evaluation of alternatives and decision-making in delicate and complex environmental domains.

\section{Enabling Cooperative Settings: A SolEuNet Example and Lessons Learned}

New media and computer networks enable business, medicine, science etc. to be done in a collaborative setting with no geographical boarders, resulting in eBusiness, eMedicine, eScience. Networked organizations are becoming increasingly important. Their activities are facilitated by the use of shared infrastructure and standards, decreasing risk and costs. A specific form of networked organizations in a virtual enterprise [Camarinha-Matos and Afsarmanesh, 2003] in which a group of organizations or individuals join voluntarily to share their knowledge and resources in order to better respond to a particular business opportunity through collaborative work, supported by information and communication technologies. Having such a possibility greatly increases possibilities of choice since one can choose their coworkers across organizational and geographical boarders, having in mind in the first place their competences to accomplish a task. Group work support systems provide technical infrastructure, so in principle, could we now work successfully with anybody in the world? 
Things again are not so simple. Kling and Lamb [2000] draw attention to the fact that interorganizational computer networks are also social networks in which relationships are complex, dynamic, negotiated and interdependent. They claim that needed organizational changes when 'going digital' are often neglected and refer to them as to 'hidden costs of computing'. We experienced this in a virtual enterprise SolEuNet (http://soleunet.ijs.si) in which 12 academic and business partners from 7 European countries joined their forces with the aim of offering their data mining and decision support expertise to the European market. Collaborative work of geographically dispersed teams had very well established Internet support and infrastructure [Jorge et al, 2003], the participants were professional experts and really devoted to the project. However, since engineering side of the project did not have a suitable counterpart at the organizational side, the organizational model evolved through different stages mainly on the basis of lessons learned during the project, including 'discovery' of the danger of information asymmetries, the importance of the IPR issues and the key role of building trust among the partners of the network [Lavrac and Urbancic, 2003]. The main direction of these changes was towards more flexibility, as in the final model, every partner of the network was given the opportunity to be the net broker in particular projects. This resulted in enhanced choice for project partners and consequently in less tensions between them.

The need of additional efforts in knowledge management [Smith and Farquhar, 2000] had to be fulfilled since in such a model, information and knowledge needed for a role of a net broker had to be organized, stored and maintained in a way that made it accessible to all partners [Jermol et al., 2004]. One of the lessons learned was that trust modelling and management should be a part of knowledge management when establishing and managing a virtual enterprise. Social network analysis as an established research field aimed at modelling social network phenomena [Wasserman and Faust, 1998] can well be used as a basis for trust modelling.

Finally, partners had to face a psychological challenge of shifting from the culture of the enterprise and the motivation of the individual towards the network culture in which sharing knowledge does not mean losing, but gaining. The concept of network intelligence as a capability of going beyond the fixed individual identity by dialogue, mutuality and trust [Palmer, 1998] is an unavoidable counterpart to technological preconditions of networked organizations. Building this kind of intelligence is a long-lasting, but very important process that should be strongly encouraged in the society, starting with education system, which, unfortunately, still strongly favourites individual competition over cooperation.

\section{Conclusion}

Enhancing human choice by technical means is important, but not sufficient for increased quality of life in the society. A decision will be in long term a good one if the process of decision-making enables cooperation of groups with different interests and is done with the responsibility towards those that can not speak for themselves but will be affected by the results of decisions (like future generations, people 
underprivileged due to their health or social status, etc.). Advances in science and technology should go hand in hand with human rights, moral issues, tolerance and responsibility.

Those that want more 'down-to-earth' reasons should bear in mind that science is mostly paid by the money that comes from taxpayers. If not for other reasons, this is why scientific community should act with a responsibility towards their needs. There is a problem due to the fact that consequences of discoveries can show up later and the history has shown that the same scientific result can be used for good or for bad. This cannot be prevented by science itself, because it will always be pushed also by pure curiosity and a wish to broaden the limits of current knowledge. What can be done by researchers with a sensitivity for social needs is to think about possible consequences of their work and to show possible benefits for the society whenever possible. Also, they should report about their work and results to a wider community, not only to their professional colleagues, explaining them in an understandable way and showing the ways the developed methods and research results can serve the goals of society. Researchers usually don't like this kind of activities, because they are time consuming and at the first glance, they don't add to their professional credit. However, things are changing. European commission requires serious justifications about expected benefits for society already at the point of project proposal submission. Also, besides technical results of a project, dissemination of results is getting increasing importance and recognition. European community as well as other bodies financing research can do a lot also when setting the priorities in their calls for proposals since in the end, the majority of research stream will go where the money will be.

To achieve the upper mentioned goals many issues will have to be considered and resolved. Designing affordable solutions represents not only a challenge to technology but it sets even new questions to the way our society operates. Let us mention the problem related to intellectual properties (IP) protection. To protect IP rights is rather expensive. How the designer of a handy affordable solution should proceed when he or she wants to make sure that the product can be produced as cheaply as possible? Is it necessary to worry about the IP rights protection at all? If one decides that he/she can do without, there is a danger that someone else can claim the IP rights and then become a monopolistic provider of a device, which will be delivered to the market for unreasonably high prise. Where to get money for appropriate protection of such products? Fortunately, in the case of software using the Open Source technology can prevent this problem. But there is no reasonable solution for HW products. Surprisingly, there are no funds to ensure IP protection for products created under support of different research grants.

So, how to achieve 'People in the first place' and 'for everybody' in the information society?

- By making information and knowledge widely accessible.

- By special care for challenged groups: adding them to be as independent as possible, to learn and live in accordance with their best abilities.

- By all people, especially those having knowledge and power, becoming 'network intelligent', i.e. understanding that sharing means gaining, not losing. Recognizing that everything is connected in a modern world, and that everybody 
has a responsibility towards other people, especially towards those that cannot speak for themselves.

- By giving credit to researchers communicating with the public. This helps in developing a sense of interconnection and responsibility.

As researchers in the IT field, we have the opportunity to focus our work towards achievements that increase quality of life in the society by offering more choice to everybody. Will we take it? And what about the society? Will it be able to create such an environment where science and technology can quickly offer all its results to the benefit of those who need it? It is not ICT itself who can offer adequate solutions for these problems. The topic calls for serious interdisciplinary dialog involving representatives of technology and humanities.

\section{Acknowledgements}

When writing the paper, the authors have been partially supported by the bilateral SICZ grants 08-2004-05 Knowledge management in medicine and health care and 21/2006-2007 Knowledge technologies in medicine and health care.

\section{References}

1. H.A. Bedau, Ethical Aspects of Environmental Decision-Making, in: Environmental Decision-Making: A Multidisciplinary Perspective, edited by H.A. Bedau, Van Nostrand Reinhold, New York, 1991, pp. 176-179.

2. M. Bohanec and V. Rajkovic, DEX: An Expert-System Shell for Decision Support, Sistemica, 1(1), 145-157 (1990).

3. M. Bohanec and V. Rajkovic, Multi-Attribute Decision Modelling: Industrial Applications of DEX, Informatica 23, 487-491 (1999)

4. G. Bruntland, editor, Our common future: The World Commission on Environment and Development, Oxford University Press, 1987.

5. L.M. Camarinha-Matos and H. Afsarmanesh, Elements of a base VE infrastructure, Journal of Computers in Industry, 51(2), 139-163 (2003).

6. M. Chorost, M. (2005) Rebuilt: How becoming part computer made me more human, Houghton Mifflin Company, 2005.

7. U. Fayyad, G. Piatetski-Shapiro, P. Smith and R. Uthurusamy, editors, Advances in Knowledge Discovery and Data Mining, MIT Press, Cambridge, MA, 1996.

8. M. Fejtova and J. Fejt, (2005): System I4CONTROL ${ }^{\circledR}$ : The Eye as a New Computer Periphery, in: The 3rd European Medical and Biological Engineering Conference EMBEC'05 [CD-ROM], Prague, 2005, vol. 11, pp. 1727-1983.

9. M. Fejtova, J. Fejt and O. Stepankova, Towards society of wisdom, in: Interdisciplinary Aspects of Human-Machine Co-existence and Co-operation, edited by V. Marik, P. Jacovkis, O. Stepankova and J. Klema, Czech Technical University Prague, 2005, pp. 253-261. 
10. D. Gamberger, G. Krstacic and N. Lavrac, Active subgroup mining: A case study in coronary heart disease risk group detection, Artificial Intelligence in Medicine, 28, 2757 (2003).

11. J. Han and M. Kamber, Data Mining: Concepts and Techniques, Morgan Kaufmann, San Francisco, 2001.

12. ICSU/UNESCO World conference on Science, Budapest (1999) Science agendaframework for action, (November 15, 2005).

http:/www.unesco.org/science/wes/eng/framework.htm

13. M. Jermol, N. Lavrac and T. Urbancic, Managing business intelligence in a virtual enterprise: a case study and knowledge management lessons learned, Journal of intelligent and fuzzy systems, vol. 14, pp. 121-136 (2004).

14. A. Jorge, D. Bojadziev, M.A. Alves, O. Stepankova, D. Mladenic, J. Palous, P. Flach and J. Petrak, Internet support to collaboration: A knowledge management and organizational memory view, in: Data mining and decision support: integration and collaboration, edited by D. Mladenic, N. Lavrac, M. Bohanec and S. Moyle, The Kluwer international series in engineering and computer science, SECS 745, Kluwer Academic Publishers, Boston, Dordrecht, London, 2003, pp. 247-259.

15. R. Kling, Fair information practices with computer supported cooperative work, Computer-Mediated Communication Magazine, 1(2), p. 5 (1994).

16. R. Kling and R. Lamb, IT and organizational change in digital economies: A sociotechnical approach, in: Understanding the Digital Economy - Data, Tools and Research, edited by B. Kahin and E. Brynjolfsson, The MIT Press, 2000.

17. B. Kontic, M. Bohanec and T. Urbancic, An experiment in participative environmental decision making, The Environmentalist, 26, 5-15 (2006).

18. N. Lavrac, M. Bohanec, A. Pur, B. Cestnik, M. Jermol, T. Urbancic, M. Debeljak, B. Kavsek, T. Kopac, Resource modelling and analysis of regional public health care data by means of knowledge technologies, in: Proceedings of the $10^{\text {th }}$ Conference on Artificial Intelligence in Medicine, AIME 2005, Aberdeen, UK, July 23-27, 2005, edited by S. Miksch, J. Hunter and E. Keravnou, Springer, Berlin, Heidelberg, New York, 2005, pp. 414-418.

19. N. Lavrac and T. Urbancic, Mind the gap: Academia-business partnership models and ecollaboration lessons learned, in: Data mining and decision support: integration and collaboration, edited by D. Mladeni, N. Lavrac, M. Bohanec and S. Moyle, The Kluwer international series in engineering and computer science, SECS 745, Kluwer Academic Publishers, Boston, Dordrecht, London, 2003, pp. 261-269.

20. E.G. Mallach, Decision Support and Data Warehouse Systems, McGraw-Hill, 2000.

21. B. McKibben, Enough: Staying Human in an Engineered Age, Owl Books, 2004.

22. J. Palmer, The Human Organization, Journal of Knowledge Management, 1(4) Number 4, 294-307 (1998).

23. R.G. Smith and A. Farquhar, The Road Ahead for Knowledge Management: An AI Perspective. AI Magazine, 21(4), 17-40 (2000).

24. The European Health Report, Health Systems Performance Assessment Methods, Annex 1 (November 15, 2005); hitp://www.euro, who.int/document/e76907.pdf

25. S. Wasserman and K. Faust, Social Network Analysis. Methods and applications, Cambridge University Press, 1998. 